\title{
Red flags for the early detection of spinal infection in back pain patients
}

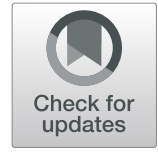

Mohamed Yusuf $^{1 *}$ (D), Laura Finucane ${ }^{2}$ and James Selfe ${ }^{1}$

\begin{abstract}
Background: Red flags are signs and symptoms that are possible indicators of serious spinal pathology. There is limited evidence or guidance on how red flags should be used in practice. Due to the lack of robust evidence for many red flags their use has been questioned. The aim was to conduct a systematic review specifically reporting on studies that evaluated the diagnostic accuracy of red flags for Spinal Infection in patients with low back pain.

Methods: Searches were carried out to identify the literature from inception to March 2019. The databases searched were Medline, CINHAL Plus, Web of Science, Embase, Cochrane, Pedro, OpenGrey and Grey Literature Report. Two reviewers screened article texts, one reviewer extracted data and details of each study, a second reviewer independently checked a random sample of the data extracted.
\end{abstract}

Results: Forty papers met the eligibility criteria. A total of 2224 cases of spinal infection were identified, of which 1385 (62\%) were men and 773 (38\%) were women mean age of $55( \pm 8)$ years. In total there were 46 items, 23 determinants and 23 clinical features. Spinal pain (72\%) and fever (55\%) were the most common clinical features, Diabetes (18\%) and IV drug use (9\%) were the most occurring determinants. MRI was the most used radiological test and Staphylococcus aureus (27\%), Mycobacterium tuberculosis (12\%) were the most common microorganisms detected in cases.

Conclusion: The current evidence surrounding red flags for spinal infection remains small, it was not possible to assess the diagnostic accuracy of red flags for spinal infection, as such, a descriptive review reporting the characteristics of those presenting with spinal infection was carried out. In our review, spinal infection was common in those who had conditions associated with immunosuppression. Additionally, the most frequently reported clinical feature was the classic triad of spinal pain, fever and neurological dysfunction.

Keywords: Back pain, Spinal pain, Serious spinal pathology, Red flags, Spinal infection, Musculoskeletal infection

\section{Background}

Medical doctors and, musculoskeletal practitioners such as Physiotherapists, Osteopaths and Chiropractors have traditionally used red flags to help in the identification of patients with serious spinal pathology. There are 163 individual items that could be considered as red flags; 119 items in the patient history and 44 items in the physical examination (CSP 2007). Clearly, this presents a problem in terms of the practical clinical utility. In addition, there is limited evidence or guidance on how these red flags should be used in practice [1-3]. Due to the lack of robust evidence for many red flags their use

\footnotetext{
*Correspondence: M.Yusuf@mmu.ac.uk

${ }^{1}$ Department of Health Professions, Manchester Metropolitan University,

Manchester M15 6GX, UK

Full list of author information is available at the end of the article
}

has been called into question $[4,5]$. However, clinicians still need to decide whether the patient's problem is suitable for immediate conservative management (keep), or whether the patient needs to be referred for further investigation (refer). Therefore in spite of no consensus in either guidelines or research, red flags are still seen as the most reliable clinical indicator for potential serious pathology and remain fundamental to the assessment process [6].

Although infections of the spine such as extra pulmonary Tuberculosis (TB) are uncommon, they are on the rise $[7,8]$. The majority of SI are of insidious onset and commonly there is a prolonged period of time between onset and diagnosis which can create a complex clinical picture as patients can remain relatively healthy

(c) The Author(s). 2019 Open Access This article is distributed under the terms of the Creative Commons Attribution 4.0 International License (http://creativecommons.org/licenses/by/4.0/), which permits unrestricted use, distribution, and 
until symptoms manifest themselves in the later stages of the disease $[9,10]$. Back pain is the most common presenting symptom which can progress to neurological symptoms and if not treated in a timely manner, lead to serious complications such as paralysis, instability of the spine and can ultimately be fatal [11-14].

Spinal infection often typically thought of as having a long prodromal period, however, Sapico and Montgomerie [10] report $30 \%$ of patients were diagnosed from three weeks to three months and $20 \%$ of patients were diagnosed in less than three weeks. In cases where there is a prolonged prodromal period, it is unsurprising that errors in the diagnosis of SI in back patients are relatively frequent [15]. When it comes to diagnostic errors in primary care, infection emerges as one of the most significant categories along with cancer and cardiovascular disease. The personal and economic consequences of these errors is significant and are a global burden [16]. For example the legal cost of errors in the diagnosis of SI in the National Health Service (NHS) in the UK is considerable. Between 2002 and 2010, SI accounted for $11.6 \%$ of all spinal related malpractice litigation, with the average damage costing the NHS $£ 433,296$ per case [17]. These figures are likely to rise, as reported by the Medical Protection Society (MPS). The clinical negligence costs over the past five years within the NHS increased by $72 \%$ and are projected to rise to $£ 2.6$ billion per year by 2022 [18].

Two of the solutions proposed by the World Health Organisation (WHO) to reduce the global burden of diagnostic errors in Primary Care are to improve diagnostic reasoning and optimise diagnostic strategies [19]. As such this review provides the basis for the construction of a robust International evidence-based clinical framework to improve the identification of patients with SI. Errors in the diagnosis of SI are reported to be as a result of two issues, first failure to recognise the relevant red flags, and second failure to consider SI as a potential differential diagnosis [20-23]. It is therefore vital that clinicians are aware of the possible signs and symptoms of SI and the risk of SI that an individual may have. When used, this knowledge will help to raise the index of suspicion and aid in the early identification of SI.

The primary aim of this study was to investigate the existing evidence to support the use of red flags for identifying Spinal Infection. Therefore, we searched the literature and reviewed studies reporting red flags in Spinal Infection patients.

\section{Methods}

This review was registered with the International Prospective Register of Systematic Reviews on 24/11/17 (PROSPERO; http://www.crd.york.ac.uk/prospero, reference: CRD42017081447). The review was conducted in concordance with the Prefered Reporting Items for Systematic Review and Meta-Analysis (PRISMA) guideline [24]. Our apriori aim was to conduct a systematic review specifically reporting on studies that evaluated the diagnostic accuracy of red flags for SI in patients with low back pain. Due to the paucity of studies evaluating the diagnostic accuracy of red flags for SI, unfortunately, it was not possible to conduct a systematic review on the diagnostic accuracy of red flags as initially intended, therefore, a descriptive review reporting on the characteristics of patients with SI was conducted.

\section{Literature search}

We searched the following electronic databases from inception to March 2019: Medline, CINHAL Plus, Web of Science, Embase, Pedro and Cochrane. In addition to this, OpenGrey and Grey Literature Report were also searched. The database searches were accompanied by hand searches of the reference list of included articles and the grey literature. With the help of the University librarian a search strategy was set in place, the three key search terms used were red flag, spinal pain and infection - see additional file 1 for the search strategy.

\section{Study selection}

Studies investigating red flags in SI were included. More specifically, the eligible studies were study designs and research articles that had primary data, this included diagnostic accuracy studies, cohort studies, case-control studies, and case-series studies. Two reviewers $(M Y$ \& $L F$ ), independently, screened the eligible papers against the full article eligibility criteria, any disagreements between the two reviewers were resolved by a third reviewer $(J S)$. Included studies were studies in the English language that studied adults over the age of 18 who had a spinal infection, this included Bacterial, Viral, Fungal, Prionic or Parasitic infections. Further, studies were included if they contained primary data such as clinical tests, diagnostic tests, history taking and/or physical examination and provided red flags or clinical features for Spinal Infection. Studies were excluded if they were a systematic review or a narrative review.

\section{Quality appraisal}

Once the full eligible papers were selected, the quality of the studies was assessed using the National Heart, Lung and blood institute (NHLBI) Quality Assessment Tools. These widely used assessment tools determine the quality of case-series, case-control and cohort studies.

\section{Data extraction}

One reviewer $(M Y)$ extracted the data from all the eligible papers. The following data were extracted from each study: study characteristics, participant 
characteristics, setting and diagnostic methods, red flags (exposures) and spinal infection (outcomes). After the data was extracted, $25 \%$ of the data was independently checked by reviewer two $(L F)$, as recommended by the 2009 Updated Method Guidelines for Systematic Reviews in the Cochrane Back Review Group [25].

\section{Data analysis}

Patient data from the included studies were analysed descriptively using frequencies and percentages.

\section{Patient and public involvement}

There were no patient or public involvement in any phase of this study, this included the development of the research question, the analysis and the conclusions.

\section{Results}

The search strategy yielded 2571 eligible papers, further narrowed down to 2274 papers after duplicates were removed. Once the eligibility criteria for the title and abstract were applied, the total came to 52 papers, of which 18 were from bibliographic searches. See Fig. 1.

\section{Study selection}

After reviewing the 52 eligible papers, 40 papers met the full eligibility criteria as agreed by the two reviewers (see additional file 1). One paper was excluded from the review because it was a narrative review [26], two papers did not include a description of the testing performed $[27,28]$ and nine papers were excluded because they did not provide data for red flags/clinical features for SI [11, 12, 28-35].

The kappa statistics for the agreement between the two reviewers was $k=0.80$, this is considered as 'Very good' [36, 37]. Reviewer three (JS) resolved the disagreement between the first two reviewers, the three discordant papers were included in the study [38-40]. All disagreements were due to criterion three, whether the papers provided clinical features for SI.

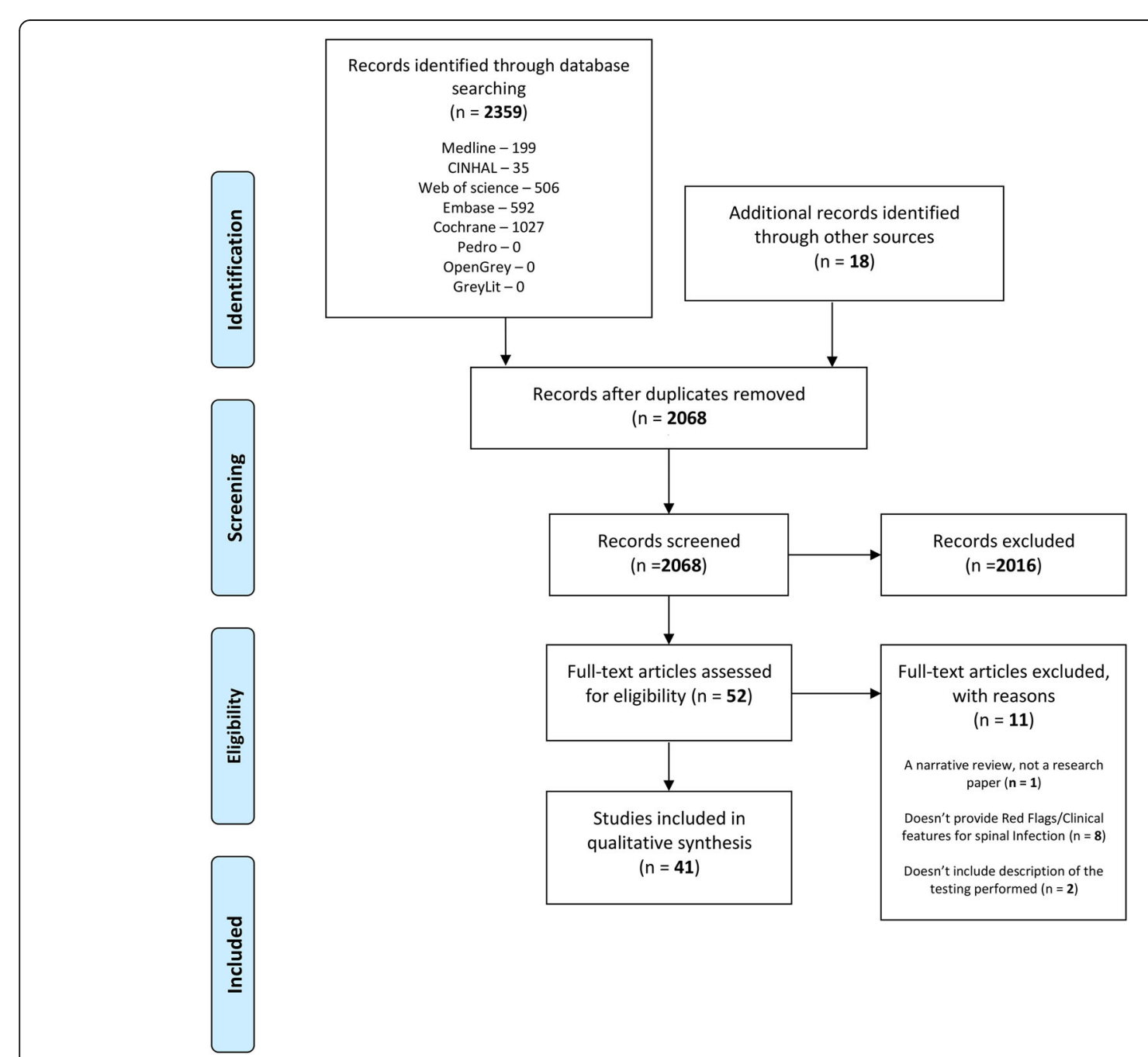

Fig. 1 PRISMA 2009 flow diagram 


\section{Characteristic of included papers}

For a summary of the main characteristics in each paper, see additional file 1 . Table 1 presents a summary of the baseline characteristics of the patients in the 40 papers reviewed. A total of 2224 patients were diagnosed, including 1385 male patients (62\%) and 773 female patients $(38 \%)$ with a mean age of 55 years $(\mathrm{SD}=8)$. In total, 14 out of 40 papers did not describe or adequately describe the radiological tests performed. This includes plain film radiography, ultrasound, magnetic resonance imaging scan (MRI), gallium scan, bone scan, computed tomography (CT) scan and myelogram [7, 13, 15, 39, 41-51]. MRI was the most used radiological test with 22 papers using it for investigation. For individual investigations, Plain radiographs and MRI were the most used radiological tests. Bone scans and Gallium scans were the most accurate tests with a positive result of 93 and $90 \%$, respectively. However, ultrasound was the least sensitive test with a positive result of $21 \%$. Out of all studies, 34 (85\%) were carried out in High-Income countries and 6 (15\%) were carried out in Upper middle-income countries, none were carried out in Lower Middle-Income and Lower Income countries.

\section{Red flags}

The list of red flags is presented in two groups, determinants and clinical features (Table 2). This decision was made because of the way in which the papers reported this information. Determinants were defined as factors that may play a part in the occurrence of SI, this included comorbidities, social factors and sources of infection that may lead to SI. Within the Dictionary of Epdimeiology, Last et al. define determinant as:

"a collective or individual risk factor (or set of factors) that is causally related to a health condition, outcome, or other defined characteristic. In human health - and, specifically, in diseases of complex etiology-determinants often act jointly in relatively complex and long-term processes. They commonly operate at aggregate (e.g., social, regional, global) levels, as well as at the individual, personal level.." [52].

Adapted from the Myriam-webster dictionary, clinical features were characterised as observable and diagnosable symptoms [53] that may occur as a consequence of SI. Here we can consider determinants as a priori red

Table 1 Study Characteristics

\begin{tabular}{|c|c|c|}
\hline Characteristics & Total & Sum of papers \\
\hline No. patients & 2224 & 40 \\
\hline Gender & & 39 \\
\hline Male (\%) & $1385(62.3)$ & \\
\hline Female (\%) & $773(37.7)$ & \\
\hline Age $($ mean $\pm S D)$ years & $55.4( \pm 8.2)$ & 35 \\
\hline Data Collection Period (mean \pm SD) years & $8( \pm 4)$ & 40 \\
\hline \multicolumn{3}{|l|}{ Diagnostic Tests positive/performed (\%) } \\
\hline Plain Radiograph & $599 / 773(77.5)$ & 14 \\
\hline MRI & $505 / 632(80.0)$ & 22 \\
\hline CT Scan & 342/395 (86.6) & 15 \\
\hline Bone Scan & 215/232 (92.7) & 11 \\
\hline Gallium Scan & $65 / 72(90.3)$ & 5 \\
\hline Myelogram & $39 / 46(84.5)$ & 3 \\
\hline Ultrasound & $8 / 39(20.5)$ & 3 \\
\hline Laboratory tests* & $2322 / 3867(60.0)$ & 33 \\
\hline Surgery & 93/112 (83.0) & 6 \\
\hline World Bank Classification by income (\%) & & 40 \\
\hline High Income (HI) & $34(85.0)$ & \\
\hline Upper Middle Income (UMI) & $6(15.0)$ & \\
\hline Lower Middle Income (LMI) & 0 & \\
\hline Lower Income (LI) & 0 & \\
\hline
\end{tabular}

*Tests included are white blood cell count (WBC), C-reactive protein (CRP) and erythrocyte sedimentation rate (ESR), pus culture, blood culture and biopsy 
Table 2 Characteristics of SI

\begin{tabular}{|c|c|c|c|c|c|}
\hline Determinants & $\begin{array}{l}\text { Total cases Reported } \\
(\%)\end{array}$ & $\begin{array}{l}\text { Sum of } \\
\text { Papers }\end{array}$ & Clinical Features & $\begin{array}{l}\text { Total cases Reported } \\
(\%)\end{array}$ & $\begin{array}{l}\text { Sum of } \\
\text { Papers }\end{array}$ \\
\hline Morbidities & & & Systemically Unwell & & \\
\hline Diabetes & $399(17.9)$ & 30 & Fever & $1225(55.1)$ & 36 \\
\hline Cancer & $112(5.5)$ & 19 & Weight loss/ Anorexia & $173(7.8)$ & 8 \\
\hline Cardiovascular disease & $109(4.9)$ & 6 & Rigours & $146(6.6)$ & 3 \\
\hline Renal failure & $56(2.5)$ & 10 & Fatigue or weakness & $102(4.6)$ & 6 \\
\hline Liver disease & $40(1.8)$ & 10 & Sweats/Night sweats & $76(3.4)$ & 5 \\
\hline Blood pressure dysfunction & $40(1.8)$ & 6 & Active infection & $54(2.4)$ & 1 \\
\hline Rheumatoid Arthritis & $35(1.6)$ & 7 & Sepsis/Septic Shock & $36(1.6)$ & 2 \\
\hline Social Factors & & & Pain & & \\
\hline Intravenous drug use & $210(9.4)$ & 15 & Spinal Pain & $1591(71.5)$ & 36 \\
\hline Corticosteroid use & $72(3.2)$ & 7 & Radiculopathy & $214(9.6)$ & 12 \\
\hline Alcoholism & $41(1.8)$ & 8 & Tenderness & $116(6.6)$ & 6 \\
\hline Triggers & & & Arthralgia & $33(1.5)$ & 3 \\
\hline Surgery & $124(5.6)$ & 10 & Myalgia & $23(1.0)$ & 3 \\
\hline Pre-existing Infection & $123(5.5)$ & 15 & Sciatic pain & $19(0.9)$ & 2 \\
\hline Immunosuppression & $96(4.3)$ & 8 & Neurological Symptoms & & \\
\hline Invasive procedure & $42(1.9)$ & 6 & $\begin{array}{l}\text { Neurological } \\
\text { dysfunction }\end{array}$ & $739(33.2)$ & 26 \\
\hline Spinal Trauma & $32(1.4)$ & 6 & Limb weakness & $175(7.9)$ & 9 \\
\hline Environmental Factors & & & Para/quadriplegia & $51(2.3)$ & 5 \\
\hline Migrant & $70(3.1)$ & 1 & Para/quadriparesis & $46(2.1)$ & 4 \\
\hline Occupational exposure & $42(1.9)$ & 3 & Paralysis & $46(2.1)$ & 2 \\
\hline Lived in rural area & $28(1.3)$ & 1 & Urological Symptoms & & \\
\hline Born in TB endemic country & $18(0.8)$ & 1 & $\begin{array}{l}\text { Bladder/bowl } \\
\text { dysfunction }\end{array}$ & $62(2.8)$ & 4 \\
\hline Behavioural Factors & & & Urinary incontinence & $21(0.9)$ & 2 \\
\hline Ingestion of unpasteurised dairy product & $61(2.7)$ & 3 & Organ Involvement & & \\
\hline Contact with infected animals & $29(1.3)$ & 1 & Hepatosplenomegaly & $21(0.9)$ & 4 \\
\hline Predisposing Factors & & & Miscellaneous & & \\
\hline None \& Miscellaneous & $116(5.2)$ & 8 & $\begin{array}{l}\text { Constitutional } \\
\text { Symptoms }\end{array}$ & $199(8.9)$ & 4 \\
\hline History of TB & $19(0.9)$ & 1 & Spinal deformity & $30(1.3)$ & 1 \\
\hline
\end{tabular}

flags leading to the development of SI, and the a posteriori as the the signs symptoms and clinical features that are present after the onset of SI.

In total there were 46 items, 23 determinants and 23 clinical features. For convenience and ease of use from a clinical perspective, the data were aggregated into relevant groups. The most frequently reported determinants were Diabetes (18\%), Intravenous drug use (9\%) and Surgery (6\%) and the most frequently reported clinical features were Spinal Pain (72\%), fever (55\%) and Neurological Dysfunction (33\%).
Other salient red flags were immunosuppression (3\%), invasive procedures $(2 \%)$, corticosteriod use $(2 \%)$, and history of TB (1\%).

The pathogens reported were Bacterial $(n=1665)$, Fungal $(n=12)$, mixed organism $(n=27)$ and unknown growth $(n=82)$, with the most common microorganisms being Staphylococcus aureus (27\%; $n=598)$, Mycobacterium tuberculosis $(12 \% ; n=262)$ and Brucella $(9 \% ; n=$ 210) (Table 3). There were no reports found on the other potential pathogenic causes of SI i.e. Viral, Prionic or Parasitic 
Table 3 Causative Pathogens

\begin{tabular}{lll}
\hline Microbiology & Total (\%) & Sum of papers \\
\hline Bacterial & $1665(74.9)$ & 37 \\
Staphylococcus aureus & $598(26.9)$ & 27 \\
Mycobacterium tuberculosis & $262(11.8)$ & 13 \\
Brucella & $210(9.4)$ & 9 \\
Streptococcus & $122(5.5)$ & 19 \\
Escherichia coli & $86(3.9)$ & 20 \\
Methicillin-resistant Staphylococcus aureus & $81(3.6)$ & 7 \\
Staphylococcus epidermitis & $53(2.4)$ & 9 \\
Psuedomonas & $32(1.4)$ & 13 \\
Methicillin-susceptible Staphylococcus aureus & $25(1.1)$ & 2 \\
Proteus & $11(0.5)$ & 5 \\
Salmonella & $10(0.4)$ & 6 \\
Staphylococcus, coagulase negative & $10(0.4)$ & 4 \\
Other & $165(7.33)$ & 16 \\
Fungal & & 7 \\
Candida & $12(0.5)$ & 7 \\
Mixed-growth & $27(1.2)$ & 7 \\
Unknown & $82(3.7)$ & 5 \\
\hline No growth & $40(1.8)$ & 5 \\
\hline
\end{tabular}

\section{Discussion}

Based on our initial search there were two potential studies evaluating the diagnostic accuracy of red flags for SI. However, just based on these two studies it was not possible to examine the diagnostic accuracy of red flags for SI, as one study combined the sensitivity and specificity for fever, spine pain, and neurologic deficits (classic triad) [54], while the other study, due to the low prevalence of SI, failed to gauge the sensitivity and specificity of red flags for SI [35]. This is consistent with the findings of Verhagen et al. in a recent systematic review looking at the red flags reported in current low back pain guidelines [3]. Spinal Infection is a relatively rare condition with an incidence of $0.2-2.4$ cases per 100,000 annually in western societies $[55,56]$, this low incidence rate makes it virtually impossible to design a prospective diagnostic study [30,32], resulting in a large body of retrospective case series and case report studies with no diagnostic accuracy data.

The majority of studies reviewed were carried out in the secondary care setting with a small number $(5 \%)$ in the primary care setting $[15,57]$. This underlines how difficult it is to identify SI in the early stages as the onset is insidious, there can be a protracted prodromal period and the clinical features are not highly specific, therefore many patients are likely to have been referred from primary care to secondary care for a diagnosis.

\section{Determinants}

Red flags currently used in clinical practice that are considered specific to infection are; the use of corticosteroids, or immunosuppressant therapy, Intravenous drug abuse, past history of $\mathrm{TB}$ and fever $[58,59]$. These, with the exception of fever, are all related to determinants rather than clinical signs of infection. The results of this paper concur and all of these determinants are reported, however, the most reported determinant was diabetes which featured in 30 papers. Although diabetes appeared as a determinant in a large number of papers it is interesting that it was only reported in $18 \%$ of patients. The review highlights that a number of morbidities such as diabetes, cancer, and HIV are among those conditions associated with immunosuppression which can consequently result in a suscebtibility to infection. Determinants such as corticosteroid use and alcohol abuse can also lead to a risk of immunodeficiency [60-63]. Also of note is that diseases such as rheumatoid arthritis and cancer sufferers treated with medications known to cause immunodeficiency (e.g. Disease-modifying anti-rheumatic drugs (DMARDS), steroids) are also at risk of SI. Determinants for SI (including intravenous drug use, diabetes and cancer) have high sensitivity (98\%) and negative predictive value (99\%) making them a better predictor of SI than clinical features such as the 
'classic triad' (spinal pain, fever and neurological dysfunction) [54].

Spinal surgery and invasive procedures are regarded as having a high risk of infection with a rate of $1-4 \%$ reported elsewhere [64]. However, in this review, surgery and invasive procedures were reported as 6 and $2 \%$, respectively. With procedural-induced SI, there are modifiable and non-modifiable determinants, such as sterility and immunological state [65-67]. Furthermore, postprocedural infection rate is highly linked to the invasiveness and complexity of the procedure carried out and the instrumentation used [68].

The overall mean age for those presenting with SI in this review was 55 years; previous research supports the notion that SI is a disease of older people [69, 70]. Amadoru et al. specifically looked at differences in presentation and outcomes between younger and older patients with SI [13]. Their findings suggested that older patients with SI present with fewer typical clinical features including fever and rigour and tend to seek medical advice later than younger patients. This could explain why age is a predictor for medical treatment failure [71]. However, the older population are also more likely to suffer from multi-morbidities which can suppress the immune system making them more susceptible to SI. A past history of TB is a question routinely asked by clinicians but it is only mentioned in one paper in this review [72]. Whilst Spinal TB is rare it is on the rise. The incidence of TB is dependent on birthplace and environmental factors, for example, born in countries with a high burden of TB, social conditions such as living in urban overcrowded conditions and homelessness. However, in this review, the social conditions reported related to rural living and occupational exposure [73].

\section{Clinical features}

The most commonly reported features of SI reported in this review were back pain, fever and neurological dysfunction which has been described elsewhere as the classic triad [54]. The classic triad is the hallmark of the SI but reliance on patients presenting with these features is likely to result in missed cases or diagnosis in the late stages as not all patients will present with all three features. The most common reported symptom in this review is that of back pain (71\%), however, back pain is usually a benign condition with a prevalence of $80 \%$ in the general population [74], which can present a diagnostic challenge for clinicians and in isolation it does not aid in identifying SI. In primary care, it is often back pain symptoms that prompt patients to seek help in the first place. Equally neurological symptoms are also reported but are also prevalent in the general population. $\mathrm{SI}$ is a progressively worsening disease with neurological deficit occurring in the later stages, whereas in the general population the expectation would be that after a period of time these neurological symptoms would resolve. Fever was the second most reported clinical feature of infection in this review. However, it was only prevalent in 55\% of patients suggesting that a lack of fever cannot rule out SI and clinicians should not necessarily be reassured by its absence. These findings are consistent with other literature [70, 75-77], with Davis et al. reporting the 'classic triad' to be $8 \%$ sensitive and $99 \%$ specific [54].

\section{Clinical presentations}

Overall, Staphylococcus aureus was the most reported cause of SI. Whereas Viral, Prionic and Parasitic causative pathogens were not reported at all. This is comparable with the wider literature as other systematic reviews also report bacterial SI, in particular, Staphylococcus aureus, to be the dominant causative SI agent [70, 76]. Though rare and not reported in this review, Viral and Parasitic SI do exist [78, 79]. In addition to this, Prionic diseases are even rarer, they are diseases of the nervous system affecting both humans and animals, there is no evidence of them affecting the musculoskeletal system, in particular, the spine [80].

\section{Diagnosis}

Despite their low sensitivity (between 43 and 75\%) [81], plain radiographs have traditionally been considered as the first step for assessing vertebral destruction $[82,83]$. $\mathrm{CT}$ and MRI scans are highly sensitive, the results in this review show that CT and MRI scans were the most accurate radiological tests for diagnosing SI. Though, it is suggested that CT scans fail to properly detect epidural abscesses and spinal cord lesions, as such they are the procedure of choice only when MRI cannot be performed [82]. Finally, due to its diagnostic accuracy and non-invasive nature, MRI is the imaging of choice when investigating suspected SI, in particular, the early stages. MRI sensitivity, specificity, and accuracy for detecting SI are reported as 96, 92, and 94\%, respectively [83-86]. Nevertheless, advanced diagnostic tools such as MRI and CT scans are costly and less available in primary care and low-income settings $[87,88]$, using them as the first diagnostic step for back pain patients is inefficient and wasteful. Therefore, it is important and costeffective for clinicians to be equipped with the red flags to screen and decide whether further diagnostic tests are needed [87]. In one of the studies reviewed, Ferrari looked at the outcome of patients with spinal pain who were not referred to advanced imaging unless they presented with red flags, he found that using red flags as the threshold before ordering advanced imaging has a low threshold for missing serious spinal pathology [31]. 


\section{Limitations}

To the author's knowledge, this is the first review to investigate the use of red flags to identify SI. This review has identified gaps in research and knowledge and recommends future areas of research [89]. Our findings should be understood in the context of some limitations. Firstly, as we were not able to identify studies presenting diagnostic accuracy of red flags for spinal infection, as a result, we presented a descriptive review of the characteristics of people with spinal infection. As there was no control group to facilitate comparison of different determinants and clinical features, we do not know whether many of these features were more common in people with spinal infection compared to those without. As these results only tell us what features are common in people with spinal infection, they cannot be relied upon for diagnosis. Secondly, most of the studies included in this review were from high income (HI) countries, yet the global burden of infections such as Spinal TB falls mostly on low income and low middle-income countries (LMI); countries where TB, Brucellosis and HIV are endemic [90]. This might suggest selection bias (Table 1) but may also be as a result of underdiagnoses and underreporting of SI in LMI countries. LMI countries tend to have weak public health infrastructure and poor health-care research capacity compared to HI countries [91]. Furthermore, the disparity in the burden of disease in LMI countries and HI means efforts and resources are prioritised to different diseases [92]. Though the potential for publication bias must not be ruled out, there is also some research alluding to the possibility of an editorial bias against the academic output from lowincome countries $[93,94]$.

\section{Recommendations}

The current evidence surrounding red flags for SI remains of low quality and clinical features alone should not be relied upon to identify SI. When a patient arrives in clinic understanding determinants of possible SI should initially be considered. These risks include immunosuppression due to co-morbidities or drug use and environmental factors (surgery and social circumstances). The prevalence of these determinants combined with the presentation of clinical features of spinal pain with possible neurological dysfunction and fever should lead to a lowered threshold (or heightened index of suspicion) to further investigate and diagnostic tests should be performed to rule out SI. MRI is the imaging technique of choice when investigating suspected SI. The authors, therefore, suggest grouping red flags into a priori and a posteriori. The a priori red flags being the comorbidities and determinants that may be present leading to the development of SI, and the a posteriori being the signs symptoms and clinical features that are present after the onset of SI. Temporally stratifying red flags in this manner will aid the clinician in building a picture based on both potential risk of SI and presentation consistent with SI.

\section{Conclusion}

Due to the paucity of literature on red flags for spinal infection, it was not possible to assess the diagnostic accuracy of red flags for spinal infection, as such, the authors conducted a descriptive review reporting the characteristics of those presenting with spinal infection was carried out. Based on the reviewed studies, spinal infection was common in those who had conditions associated with immunosuppression. Additionally, the most frequently reported clinical feature was the classic triad of spinal pain, fever and neurological dysfunction.

\section{Abbreviations \\ CRP: C-Reactive Protein (CRP); CT: Computed Tomography; DMARDS: Disease-Modifying Anti-rheumatic Drugs; ESR: Erythrocyte Sedimentation Rate (ESR); HIV: Human Immunodeficiency Virus; MPS: Medical Protection Society; MRI: Magnetic Resonance Imaging scan; ND: No data; NHS: National Health Service; NNHLBI: National Heart, Lung and blood institute; PROSPERO: Prospective Register of Systematic Reviews; SI: Spinal Infection; TB: Tuberculosis; WBC: World Bank Classification; WHO: World Health Organisation}

\section{Acknowledgements \\ We to thank the CSP for commissioning and funding this project, making it possible. We would also like to thank the liberarian at Manchester Metropolitan university for kindly supporting us with the search strategy.}

\section{Authors' contributions}

$J \mathrm{~S}$ is a guarantor of this review. All authors have made substantive intellectual contributions to the development of this review. JS and LF were involved in conceptualising the review. MY and JS developed the protocol. MY did the literature search, both MY and LF carried out the study selection and data extraction. All three authors contributed to the writing and editing of the manuscript. All authors gave approval for the final version.

\section{Funding}

This work is commissioned by the Chartered Society of Physiotherapy (CSP). (there is no funding number associated with this project). The CSP is the professional, educational and trade union body for those who deliver physiotherapy care, education and research in the UK. This work was conducted independently by the research team, there is no political/ lobbying/advocacy conflicts of interest between the CSP and the work produced and/or its application to clinical practice.

Availability of data and materials

All data generated or analysed during this study are included in this published article.

Ethics approval and consent to participate

Not applicable.

\section{Consent for publication}

Not applicable.

\section{Competing interests}

All authors have completed the ICMJE uniform disclosure form at wwW. icmje.org/coi_disclosure.pdf and declare: no financial relationships with any organisations that might have an interest in the submitted work in the previous three years; no other relationships or activities that could appear to have influenced the submitted work. 


\section{Author details}

'Department of Health Professions, Manchester Metropolitan University, Manchester M15 6GX, UK. ² Sussex Musculoskeletal Partnership, Brighton, UK

Received: 28 March 2019 Accepted: 14 November 2019

Published online: 13 December 2019

\section{References}

1. Henschke N, Maher CG, Refshauge KM, Herbert RD, Cumming RG, Bleasel J, York J, Das A, McAuley JH. Prognosis of acute low back pain: design of a prospective inception cohort study. BMC Musculoskelet Disord. 2006:7:54.

2. Downie A, Williams CM, Henschke N, Hancock MJ, Ostelo RWJG, de Vet HCW, Macaskill P, Irwig L, van Tulder MW, Koes BW, et al. Red flags to screen for malignancy and fracture in patients with low back pain: systematic review. BMJ : British Med J. 2013;347.

3. Verhagen AP, Downie A, Popal N, Maher C, Koes BW. Red flags presented in current low back pain guidelines: a review. Eur Spine J. 2016;25(9):2788-802

4. Underwood M, Buchbinder R. Red flags for back pain. BMJ. 2013;347:f7432

5. Cook CE, George SZ, Reiman MP. Red flag screening for low back pain: nothing to see here, move along: a narrative review. Br J Sports Med. 2017.

6. Ferguson F, Holdsworth L Fau Rafferty D, Rafferty D: Low back pain and physiotherapy use of red flags: the evidence from Scotland. (1873-1465 (Electronic))

7. Pigrau-Serrallach C, Rodríguez-Pardo D. Bone and joint tuberculosis. Eur Spine J. 2013;22(4):556-66.

8. Nagashima $\mathrm{H}$, Tanishima S, Tanida A. Diagnosis and management of spina infections. J Orthop Sci. 2018;23(1):8-13.

9. Wainwright A: Infections of the spine. In: Management of low back pain in primary care. 1 edn. Edited by Richard Bartley PC. Oxford: ButterworthHeinemann; 2001: 99.

10. Sapico FL, Montgomerie JZ. Pyogenic vertebral osteomyelitis: report of nine cases and review of the literature. Rev Infect Dis. 1979;1(5):754-76.

11. McHenry MC, Easley KA, Locker GA. Vertebral osteomyelitis: long-term outcome for 253 patients from 7 Cleveland-area hospitals. Clin Infect Dis. 2002:34(10):1342-50.

12. Hadjipavlou AG, Mader JT, Necessary JT, Muffoletto AJ. Hematogenous pyogenic spinal infections and their surgical management. Spine. 2000; 25(13):1668-79.

13. Amadoru S, Lim K, Tacey M, Aboltins C. Spinal infections in older people: an analysis of demographics, presenting features, microbiology and outcomes. Intern Med J. 2017:47(2):182-8.

14. Colmenero JD, Jiménez-Mejías ME, Sánchez-Lora FJ, Reguera JM, PalominoNicás J, Martos F, García de las Heras J, Pachón J. pyogenic, tuberculous, and brucellar vertebral osteomyelitis: a descriptive and comparative study of 219 cases. Ann Rheum Dis 1997, 56(12):709-715.

15. Bhise V, Meyer AND, Singh H, Wei L, Russo E, Al-Mutairi A, Murphy DR Errors in diagnosis of spinal epidural abscesses in the era of electronic health records. Am J Med. 2017;130(8):975-81.

16. Singh H, Schiff GD, Graber ML, Onakpoya I, Thompson MJ. The global burden of diagnostic errors in primary care. BMJ Quality \& Safety. 2016.

17. Quraishi NA, Hammett TC, Todd DB, Bhutta MA, Kapoor V. Malpractice litigation and the spine: the NHS perspective on 235 successful claims in England. Eur Spine J. 2012;21(Suppl 2):S196-9.

18. Society MP: The Rising Costs of Clinical Negligence: Who pays the Price? In.; 2017.

19. Organization WH: Medication errors. In.; 2016.

20. Pope JV, Edlow JA. Avoiding misdiagnosis in patients with neurological emergencies. Emerg Med Int. 2012;2012:949275.

21. Liou LM, Shih PY. Epidural abscess of the cervical spine with atypical manifestations: a report of two cases. Neurologist. 2007;13(4):215-8.

22. Patel D, Baron EM, Enochs WS, Ruth C, Harrop JS, Vaccaro AR. Spinal epidural abscess mimicking lymphoma: a case report. Orthopedics. 2008; 31(4):402.

23. Khoriati A, Kitson J, Deol RS. Cervical spinal abscess: an insidious presentation and unusual pathology. Ann R Coll Surg Engl. 2012;94(6): e184-5.

24. Liberati A, Altman DG, Tetzlaff J, Mulrow C, Gøtzsche PC, loannidis JPA, Clarke M, Devereaux PJ, Kleijnen J, Moher D. The PRISMA statement for reporting systematic reviews and meta-analyses of studies that evaluate healthcare interventions: explanation and elaboration. BMJ. 2009;339.
25. Furlan AD, Pennick V, Bombardier C, van Tulder M. Group ftEBotCBR: 2009 updated method guidelines for systematic reviews in the Cochrane Back review group. Spine. 2009;34(18):1929-41.

26. Turgut M. Spinal tuberculosis (Pott's disease): its clinical presentation, surgical management, and outcome. A survey study on 694 patients. Neurosurg Rev. 2001;24(1):8-13.

27. Goel V, Young JB, Patterson CJ. Infective discitis as an uncommon but important cause of back pain in older people. Age Ageing. 2000;29(5): 454-6.

28. Edwards MA, Hawkins M, Alao D. Missing red flags in back pain-tuberculosis of the spine: an important differential for back pain in nonendemic countries. BMJ Case Rep. 2013;2013.

29. Quesnele J, Dufton J, Stern P. Spinal infection: a case report. J Canadian Chiropr Association. 2012;56(3):209-15.

30. Henschke N, Maher CG, Refshauge KM, Herbert RD, Cumming RG, Bleasel J, York J, Das A, McAuley JH. Prevalence of and screening for serious spinal pathology in patients presenting to primary care settings with acute low back pain. Arthritis Rheumatol. 2009;60(10):3072-80.

31. Ferrari R. Imaging studies in patients with spinal pain: practice audit evaluation of choosing wisely Canada recommendations. Can Fam Physician. 2016:62(3):e129-37.

32. Enthoven WT, Geuze J, Scheele J, Bierma-Zeinstra SM, Bueving HJ, Bohnen AM, Peul WC, van Tulder MW, Berger MY, Koes BW. Prevalence and "red flags" regarding specified causes of back pain in older adults presenting in general practice. Phys Ther. 2016;96(3):305-12.

33. Zarrouk V, Feydy A, Sallès F, Dufour V, Guigui P, Redondo A, Fantin B. Imaging does not predict the clinical outcome of bacterial vertebral osteomyelitis. Rheumatol. 2007:46(2):292-5.

34. Ledermann HP, Schweitzer ME, Morrison WB, Carrino JA. MR imaging findings in spinal infections: rules or myths? Radiology. 2003;228(2):506-14.

35. Tsiang JT, Kinzy TG, Thompson N, Tanenbaum JE, Thakore NL, Khalaf T, Katzan IL. Sensitivity and specificity of patient-entered red flags for lower back pain. Spine J. 2019;19(2):293-300.

36. Jacob C. A coefficient of agreement for nominal scales. Educ Psychol Meas. 1960;20(1):37-46.

37. Landis JR, Koch GG. The measurement of observer agreement for categorical data. Biometrics. 1977;33(1):159-74.

38. Carragee EJ. Pyogenic vertebral osteomyelitis. JBJS. 1997:79(6):874-80.

39. Kapsalaki E, Gatselis N, Stefos A, Makaritsis K, Vassiou A, Fezoulidis I, Dalekos GN. Spontaneous spondylodiscitis: presentation, risk factors, diagnosis, management, and outcome. Int J Infect Dis. 2009;13(5):564-9.

40. Huang J-J, Ruaan M-K, Lan R-R, Wang M-C. Acute pyogenic iliopsoas abscess in Taiwan: clinical features, diagnosis, treatments and outcome. J Infect. 2000;40(3):248-55

41. Chelsom J, Solberg CO. Vertebral osteomyelitis at a Norwegian university hospital 1987-97: clinical features, laboratory findings and outcome. Scand Infect Dis. 1998:30(2):147-51.

42. Yilmaz E, Parlak M, Akalin H, Heper Y, Ozakin C, Mistik R, Oral B, Helvaci S, Tore O. Brucellar spondylitis - review of 25 cases. Jcr-J Clinical Rheumatol. 2004;10(6):300-7.

43. Yee DKH, Samartzis D, Wong Y-W, Luk KDK, Cheung KMC. Infective spondylitis in southern Chinese: a descriptive and comparative study of ninety-one cases. Spine. 2010;35(6):635-41.

44. Suzuki H, Shichi D, Tokuda Y, Ishikawa H, Maeno T, Nakamura H. Pneumococcal vertebral osteomyelitis at three teaching hospitals in Japan, 2003-2011: analysis of 14 cases and a review of the literature. BMC Infect Dis. 2013;13.

45. Tang HJ, Lin HJ, Liu YC, Li CM. Spinal epidural abscess--experience with 46 patients and evaluation of prognostic factors. J Inf Secur. 2002;45(2):76-81.

46. Huang PY, Chen SF, Chang WN, Lu CH, Chuang YC, Tsai NW, Chang CC, Wang HC, Chien CC, Chen SH, et al. Spinal epidural abscess in adults caused by Staphylococcus aureus: clinical characteristics and prognostic factors. Clin Neurol Neurosurg. 2012;114(6):572-6.

47. Patel AR, Alton TB, Bransford RJ, Lee MJ, Bellabarba CB, Chapman JR. Spinal epidural abscesses: risk factors, medical versus surgical management, a retrospective review of 128 cases. Spine J. 2014;14(2):326-30.

48. Kaya S, Ercan S, Aktas U, Kamasak K, Ozalp H, Cinar K, Duymus R, Boyaci MG, Akkoyun N, Eskazan AE, et al. Spondylodiscitis: evaluation of patients in a tertiary hospital. J Infect Dev Ctries. 2014:8(10):1272-6.

49. Narváez J, Nolla JM, Narváez JA, Martinez-Carnicero L, De Lama E, GómezVaquero C, Murillo O, Valverde J, Ariza J. Spontaneous pyogenic facet joint infection. Semin Arthritis Rheum. 2006;35(5):272-83. 
50. Turunc T, Ziya Demiroglu Y, Uncu H, Colakoglu S, Arslan H. A comparative analysis of tuberculous, brucellar and pyogenic spontaneous spondylodiscitis patients. J Infect. 2007;55(2):158-63.

51. Lu C-H, Chang W-N, Lui C-C, Lee P-Y, Chang H-W. Adult spinal epidural abscess: clinical features and prognostic factors. Clin Neurol Neurosurg. 2002;104(4):306-10.

52. Last JM, Abramson JH, Freidman GD: A dictionary of epidemiology, vol. 4: Oxford University Press New York; 2001.

53. Title [https://www.merriam-webster.com/dictionary/clinical].

54. Davis DP, Wold RM, Patel RJ, Tran AJ, Tokhi RN, Chan TC, Vilke GM. The clinical presentation and impact of diagnostic delays on emergency department patients with spinal epidural abscess. J Emerg Med. 2004;26(3):285-91.

55. Lam KS, Webb JK. Discitis. Hospital Med. 2004;65(5):280-6.

56. Hopkinson N, Stevenson J, Benjamin S. A case ascertainment study of septic discitis: clinical, microbiological and radiological features. QJM: Monthly J Association Phys. 2001;94(9):465-70.

57. Sakeni RA, Al-Nimer MSM. Infectious discitis in adults: 9 years experience from Al-Yarmouk teaching Hospital in Baghdad, Iraq. Int J Rheum Diseases. 2008;11(2):175-80

58. Greenhalgh SS, J: Red Flags II: A Clinical Guide to Solving Serious Spinal Pathology: Churchill Livingstone, Elsevier. ; 2010.

59. Sciatica (lumbar radiculopathy) [https://cks.nice.org.uk/sciatica-lumbarradiculopathy\#!diagnosissub:1].

60. Casqueiro J, Casqueiro J, Alves C. Infections in patients with diabetes mellitus: a review of pathogenesis. Indian J Endocrinol Metab. 2012; 16(Suppl1):S27-36.

61. Rolston KVI. Infections in Cancer patients with solid tumors: a review. Infect Dis Ther. 2017;6(1):69-83.

62. Sadek MS, Abd-el-Hamid T, Hussein S. Infection in immunosuppressed patients. Chemioterapia: int j Mediterr Soc Chemother. 1984;3(1):19-24.

63. Cohen J, Pinching A, Rees A, Peters D. Infection and immunosuppression: a study of the infective complications of 75 patients with immunologicallymediated disease. QJM: An Int J Med. 1982;51(1):1-15.

64. Klemencsics I, Lazary A, Szoverfi Z, Bozsodi A, Eltes P, Varga PP. Risk factors for surgical site infection in elective routine degenerative lumbar surgeries. Spine J. 2016;16(11):1377-83.

65. Chaudhary SB, Vives MJ, Basra SK, Reiter MF. Postoperative spinal wound infections and postprocedural diskitis. In: Taylor Francis. 2007.

66. Cunningham ME, Girardi F, Papadopoulos EC, Cammisa FP. Spinal infections in patients with compromised immune systems. Clin Orthop Relat Res. 2006;444:73-82.

67. Parchi PD, Evangelisti G, Andreani L, Girardi F, Darren L, Sama A, Lisanti M. Postoperative spine infections. Orthop Rev. 2015;7(3):5900.

68. Gelalis ID, Arnaoutoglou CM, Politis AN, Batzaleksis NA, Katonis PG, Xenakis TA. Bacterial wound contamination during simple and complex spinal procedures. A prospective clinical study. Spine J. 2011;11(11):1042-8.

69. Sobottke R, Röllinghoff M, Zarghooni K, Zarghooni K, Schlüter-Brust K, Delank K-S, Seifert H, Zweig T, Eysel P. Spondylodiscitis in the elderly patient: clinical mid-term results and quality of life. Arch Orthop Trauma Surg. 2010;130(9):1083-91.

70. Mylona E, Samarkos M, Kakalou E, Fanourgiakis P, Skoutelis A. Pyogenic vertebral osteomyelitis: a systematic review of clinical characteristics. Semin Arthritis Rheum. 2009;39(1):10-7.

71. Stratton A, Gustafson K, Thomas K, James MT. Incidence and risk factors for failed medical management of spinal epidural abscess: a systematic review and meta-analysis. J Neurosurg Spine. 2017;26(1):81-9.

72. Pertuiset E, Beaudreuil J, Lioté F, Horusitzky A, Kemiche F, Richette P, ClercWyel D, Cerf-Payrastre I, Dorfmann H, Glowinski J. Spinal tuberculosis in adults. A study of 103 cases in a developed country, 1980-1994. Medicine. 1999;78(5):309-20.

73. Narasimhan P, Wood J, Maclntyre CR, Mathai D. Risk factors for tuberculosis. Pulmonary Medicine. 2013;2013:828939.

74. Rubin DI. Epidemiology and risk factors for spine pain. Neurol Clin. 2007; 25(2):353-71.

75. Uckay I, Dinh A, Vauthey L, Asseray N, Passuti N, Rottman M, Biziragusenyuka J, Riché A, Rohner P, Wendling D. Spondylodiscitis due to Propionibacterium acnes: report of twenty-nine cases and a review of the literature. Clin Microbiol Infect. 2010;16(4):353-8.

76. Reihsaus E, Waldbaur H, Seeling W. Spinal epidural abscess: a meta-analysis of 915 patients. Neurosurg Rev. 2000;23(4):175-204.
77. Deyo RA, Rainville J, Kent DL. What can the history and physical examination tell us about low back pain? Jama. 1992;268(6):760-5.

78. Do Amaral LL, Nunes R, Rocha A: Parasitic and Rare Spinal Infections, vol. 25; 2015.

79. Irani DN. Aseptic Meningitis and Viral Myelitis. Neurologic clinics. 2008;26(3): 635-viii.

80. Kovacs GG, Budka H. Prion diseases: from protein to cell pathology. Am J Pathol. 2008;172(3):555-65

81. Palestro CJ, Love C, Miller TT. Imaging of musculoskeletal infections. Best Pract Res Clin Rheumatol. 2006;20(6):1197-218.

82. Balériaux DL, Neugroschl C. Spinal and spinal cord infection. Eur Radiol Suppl. 2004;14(3):E72-83

83. Cheung WY, Luk KDK. Pyogenic spondylitis. Int Orthop. 2012;36(2):397-404.

84. An HS, Seldomridge JA. Spinal infections: diagnostic tests and imaging studies. Clin Orthop Relat Res. 2006:444:27-33.

85. Sendi P, Bregenzer T, Zimmerli W. Spinal epidural abscess in clinical practice. QJM. 2008;101(1):1-12.

86. Lury K, Smith JK, Castillo M. Imaging of spinal infections. Semin Roentgenol. 2006;41(4):363-79.

87. Joines JD, McNutt RA, Carey TS, Deyo RA, Rouhani R. Finding Cancer in primary care outpatients with low Back pain: a comparison of diagnostic strategies. J Gen Intern Med. 2001;16(1):14-23.

88. Musubire AK, Meya DB, Bohjanen PR, Katabira ET, Barasukana P, Boulware DR, Meyer A-C. A Systematic Review of Non-Traumatic Spinal Cord Injuries in Sub-Saharan Africa and a Proposed Diagnostic Algorithm for ResourceLimited Settings. Front Neurol. 2017;8(618).

89. Arksey H, O'Malley L. Scoping studies: towards a methodological framework. Int J Soc Res Methodol. 2005;8(1):19-32.

90. Held MFG, Hoppe S, Laubscher M, Mears S, Dix-Peek S, Zar HJ, Dunn RN. Epidemiology of musculoskeletal tuberculosis in an area with high disease prevalence. Asian Spine J. 2017;11(3):405-11.

91. Kirigia JM, Wambebe C. Status of national health research systems in ten countries of the WHO African region. BMC Health Serv Res. 2006:6(1):135.

92. Global, regional, and national disability-adjusted life-years (DALYs) for 333 diseases and injuries and healthy life expectancy (HALE) for 195 countries and territories, 1990-2016: A systematic analysis for the global burden of disease study 2016. The Lancet 2017, 390(10100):1260-1344.

93. Yousefi-Nooraie R, Shakiba B, Mortaz-Hejri S. Country development and manuscript selection bias: a review of published studies. BMC Med Res Methodol. 2006;6:37.

94. Harris M, Macinko J, Jimenez G, Mahfoud M, Anderson C. Does a research article's country of origin affect perception of its quality and relevance? A national trial of US public health researchers. BMJ Open. 2015;5(12):e008993.

\section{Publisher's Note}

Springer Nature remains neutral with regard to jurisdictional claims in published maps and institutional affiliations.

Ready to submit your research? Choose BMC and benefit from:

- fast, convenient online submission

- thorough peer review by experienced researchers in your field

- rapid publication on acceptance

- support for research data, including large and complex data types

- gold Open Access which fosters wider collaboration and increased citations

- maximum visibility for your research: over $100 \mathrm{M}$ website views per year

At $\mathrm{BMC}$, research is always in progress.

Learn more biomedcentral.com/submission 